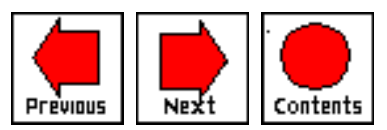

\title{
VIRTUAL REALITY AND BODY EXPERIENCE: A NEW APPROACH TO THE TREATMENT OF EATING DISORDERS
}

Editor: Max M. North

\section{ABSTRACT}

Giuseppe Riva \{ $\{$ contact info $\}\}$

Centro Auxologico Italiano

Intra, Italy

Editor: Max M. North

\section{ABSTRACT}

Eating Disorders, one of the most common pathologies of the occidental society, have long been associated with alterations in the perceptual/cognitive representations of the body. In fact, a large number of studies have highlighted the fact that the perception of one's own body and the experiences associated with it represent one of the key problems of anorexic, bulimic and obese subjects. The effects have a strong influence on therapy effects: severe body representation disturbance is predictive of treatment failure. However, the treatment of body experience problems is not well defined. Two methods are currently in use: the first is a cognitive/behavioral approach aimed at influencing patients' feelings of dissatisfaction; the second is a visual/motorial approach with the aim of influencing the level of bodily awareness.

The Virtual Environment for Body Image Modification (VEBIM), a set of tasks aimed at treating body image, tries to integrate these two therapeutic approaches within an immersive virtual environment.

This choice not only makes it possible to intervene simultaneously on all of the forms of bodily representations, but it also uses the psycho-physiological effects 
provoked on the body by the virtual experience for therapeutic purposes. This paper describes the VEBIM theoretical approach and its characteristics. It also presents a study on a preliminary sample (60 normal subjects) to test the efficacy of this approach.

\section{Introduction}

The perceptual world created by our senses and our mind is so functional a representation of the physical world that most people live out their lives without ever suspecting that contact with the physical world is mediate. The physical world, including our body, is not given directly in our experience, but is inferred through observation and critical reasoning. This means that in everyday life the body, as a representation/image/idea, plays an important and often under-rated role. It is interesting to note that these representations are not limited to visual "images" (i.e., pictures in one's head of one's body), but comprise the schema of all sensory input internally and externally derived -- lived experiences processed and represented within a maturing psychic apparatus.

\subsection{BODY SCHEMA AND BODY IMAGE}

This "virtual body" has been the subject of a number of studies which often make reference to differing concepts and theories: "body percept", "body image", "body concept", "body schema" and "body values". Recently an attempt has been made to incorporate all of the forms of perceptive/cognitive representation of the human body within two fundamental concepts [Gallagher, 1986], [Gallagher, 1995], [Fisher, 1990]: body schema and body image.

According to Head [Head, 1926], the body schema is a model/representation of one's own body that constitutes a standard against which postures and body movements are judged. This representation can be considered the result of comparisons and integrations at the cortical level of past sensory experiences (postural, tactile, visual, kinesthetic and vestibular) with current sensations. This gives rise to an almost completely unconscious "plastic" reference model that makes it possible to move easily in space and to recognize the parts of one's own body in all situations.

If the body schema can be considered a perceptual model of the body, the body image is a cognitive/ social/emotional model. In fact, body image is not only a cognitive construction but also a reflection of wishes, emotional attitudes and interactions. According to Schilder [Shilder, 1950], the body image can be defined as "the picture of our own body which we form in our mind, that is to say, the way in which the body appears to ourselves" (p. 11). Expanding on Schilder's idea, Allamani et al. [Allamani, et. al., 1990] refer to body image as "a complex psychological organization which develops through the bodily 
experience of an individual and affects both the schema of behavior and a fundamental nucleus of self-image" (p. 121).

The circular interaction among behaviors, emotions and cognitions we find in body image can be explained by the rational-emotive model [Ellis, 1962], [Freedman, 1990]: X, an activating event (e.g. wearing a skirt), leads to Y, a bridging thought and self statement (e.g. "I'm too big"), which triggers $\mathrm{Z}$, a conditioned emotional response (e.g. disgust, anxiety). In this way $\mathrm{X}$, the activating event, generates new cognitions which then induce new feeling (e.g. "I'm fat") and behavior (e.g. dieting). Behavioral disturbances may thus be both a cause and an effect of faulty thinking.

\subsection{HOW BODY SCHEMA CAN AFFECT BODY IMAGE}

Gallagher [Gallagher, 1995] analyzed recent psychological studies on the relationship between body image and body schema. His report stated that performances of the body schema may place constraints on intentional consciousness. In particular, the studies indicate that changes in various aspects of body schema have an effect on the way subjects perceive their own bodies, that is, changes in body schema lead to changes in body images. More generally, changes in body schema also affect spatial perception and perception of objects. Here are some of the examples reported in the paper:

- Exercise, dance, and some other practices that affect motility and the postural schema have an effect on the emotive evaluation of one's own body image [Adame et al., 1991], [Dasch, 1978] [Davis \& Cowles, 1991], [Skrinar et al., 1986]. In these studies subjects who through exercise improve in neuromuscular coordination strength, and endurance, or experience increased coordination, balance, agility, and Improved posture, gain a perception of body competence and achieve a higher degree of satisfaction with their own bodies. Thus changes in body schema associated with exercise alter the way that subjects emotionally relate to and perceive their bodies.

- Changes in muscular schemata correlate with changes in the subject's bodily awareness and perceptual awareness of the environment [Rugqieri et al., 1983], [Sabatini, Ruggieri, \& Milizia, 1984]. These studies also suggest that unconscious adjustments of the body schema allow the subject to direct attention to external rather than internal stimuli. More generally, to the extent that the body schema makes its prenoetic adaptations to the environment and remains in the perceptual background, cognitive attention can be focused elsewhere in any variety of intentions.

- Retardation in the development of the body schema caused, for example, by an absence of early crawling experience, has a negative effect on the development of spatial perception. Studies by Joseph Campos and his 
colleagues have demonstrated that crawling and locomotor experience in infants have an effect on the perception and evaluation of spatial heights [Campos, Bertenthal, \& Kermoian, 1992].

- Several studies indicate that proprioceptive adjustments of the body schema help to resolve perceptual conflicts. Adaptation in the realm of visual experience involves changes in proprioceptive information. For example, perceptually adapting to 180 degree rotation of the retinal image is facilitated by "changes in the position sense for various parts of the body" [Harris, 1965, p. 419].

- Experimental studies indicate that there is a "close linkage between eye posture or movements and the spatial organization of the whole-body posture" [Roll \& Roll 1988, p. 159]. Thus vibration of extraocular eye muscles result in body sways and shifts in balance. Also, vibration-induced proprioceptive patterns that change the posture of the whole body are interpreted as changes in the perceived environment. It follows that alterations in proprioceptive information, information closely connected to the organization of the body schema, lead to changes in visual perception.

In all of these cases changes or distortions introduced at the level of the body schema result in changes or distortions in intentional consciousness. This simply reflects the general rule. In all cases performances of the body schema influence intentionality. They operate as constraining and enabling factors that limit and define the possibilities of intentional consciousness.

\subsection{DEFINITION OF BODY EXPERIENCE DISTURBANCE}

Body experience disturbance has been used by a wide variety of researchers and clinicians to designate a great number of phenomena with little or no overlapping characteristics [Thompson, 1992], For instance, the term has been used to refer to phantom limb syndrome, neuropsychological deficits (anosognosia), and the psychodynamic concept of "body boundary" [Thompson, 1990], In this paper we focus exclusively on a physical appearance related definition that is quite broad: body experience disturbance is any form of affective, cognitive, behavioral, or perceptual disturbance that is directly concerned with an aspect of physical appearance.

\section{Body Experience and Eating Disorders}

Body experience has a long and storied association with eating and weight related problems [Stunkard \& Mendelson, 1961], [Bruch, 1962], [Bruch, 1973], [Garfinkel \& Garner, 1982], [Barrios et al., 1989], [Rosen, 1990] [Thompson, 1990], [Valtolina et al., 1994], [Thompson, 1995]. Bruch [Bruch, 1962] articulated the integral role of body experience in the development, 
maintenance, and treatment of anorexia nervosa. In recent years researchers agree that body experience is a central factor in bulimia nervosa [American Psychiatric Association, 1994], [Thompson, Berland, Linton, \& Weinsier, 1986]. Finally, although often ignored as a feature of obesity (see [Thompson, 1990] Stunkard and Burt [Stunkard \& Burt, 1967] demonstrated almost 30 years ago the importance of body experience to an understanding of individuals with excessive weight.

One index of the importance of body experience disturbance involves its relevance to agreed-on clinical disorders. The Diagnostic and Statistical Manual of Mental Disorders IV [American Psychiatric Association, 1994] contains a body image criterion that is required for the diagnosis of anorexia nervosa or bulimia nervosa. It has also been suggested that when there is psychological comorbidity with obesity, it may be strongly due to problematic body experience issues [Thompson, 1992]. Today, researchers and clinicians agree that including an assessment and evaluation of body experience disturbance is crucial to any treatment program targeting obesity or eating disorders.

Some studies concerning the efficacy of the cognitive-behavioral treatment of anorexia have indicated that patients who make a larger overestimate of their own body dimensions [Casper et al., 1979], or who are more pleased with their own physical appearance [Vandereychken et al., 1988], gain less weight after a period of treatment. Furthermore, among those who manage to reach their target weight, post-treatment weight loss correlates directly with the way in which patients perceive their own size [Button, 1986]. Also in the treatment of bulimic subjects, body experience has been shown to play an important role in assessing the outcome of treatment. In particular, the degree of satisfaction that patients have in relation to their bodies has been shown to be related both to a reduction in bulimic behavior and to subsequent relapses [Conners et al., 1984], [Freeman et al., 1985]

In contrast to the great number of publications on body image, only a few papers focus on the treatment of a disturbed body image in eating disorders. In general, two direct and specific approaches can be distinguished: a cognitive/behavioral approach aimed at influencing patients' feelings of dissatisfaction with different parts of their bodies by means of individual interviews, relaxation and imaginative techniques [Butters \& Cash, 1987], and a visual/motor approach which makes use of video recordings of particular gestures and movements with the aim of influencing the level of bodily awareness [Wooley \& Wooley, 1985].

\section{Virtual Reality and Body Experience}

Virtual reality (VR) is a medium that is defined in terms of its effects on basic 
perception and higher order psychological processes [Durlach, 1992], [Ellis, Kaiser \& Grunwald, 1991]. Steuer [Steuer, 1992] defines VR in terms of human experience as "a real or simulated environment in which a perceiver experiences telepresence". In fact, VR creates a sense of personal presence by simulating as closely as possible the range and intensity of stimuli that human senses detect in perceiving the natural world. In immersion VR you know you are "there" because the virtual world responds like the real world to your body and head movements [Heeter, 1992].

\subsection{A NEW CHALLENGE}

An interesting possibility could be the integration of the two methods (cognitive-behavioral and visual-motor) commonly used in the treatment of body experience disturbances within a virtual environment. In particular, we tried to integrate them using the virtual environment in the same way as images in the well-known method of guided imagery [Leuner, 1969]. According to this method the therapist, after introducing a selected image, encourages the patient to associate to it in pictures, rather than in words, and to give a detailed description of them. Leuner's belief is that the imagery evokes intense latent feelings that are relevant to the patient's problems. Guided imagery has been found to be a powerful tool in treatment ranging from psychoanalytic therapy [Reyker, 1977] to behaviorism [Wolpe, 1958].

A choice of this type only makes it possible to evoke latent feelings, but also uses the psycho-physiological effects provoked by the experience for therapeutic purposes. It is well known that in practically all VR systems the human operator's normal sensorimotor loops are altered by the presence of distortions, time delays and noise in the system. Such alterations, introduced unintentionally and usually degrading performance, affect body perceptions also. The somesthetic systems has a proprioceptive subsystem that senses the body's internal state, such the position of limbs and joints and the tension of the muscles and tendons. Mismatches between the signals from the proprioceptive system and the external signals of a virtual environments alter body perceptions and can cause discomfort or simulator sickness [Sadowsky \& Massof, 1994].

In a recent study, Cioffi [Cioffi, 1993] analyzed these effects and found that in a virtual reality the self-perception of one's own body undergoes profound changes similar to those achieved in the 1960s by many psychologists in their studies of perceptual distortion. In particular, about $40 \%$ of the subjects felt as if they had "dematerialized" or as if they were in the absence of gravity. Moreover, $44 \%$ of the men and $60 \%$ of the women claimed not to feel their bodies. Perceptual distortions, leading to a few seconds of instability and a mild sense of confusion, were also observed in the period immediately following the virtual experience. 
Such effects, attributable to the reorganizational and reconstructive mechanisms necessary to adapt the subjects to the qualitatively distorted world of VR, could be of great help during the course of a therapy aimed at influencing the way the body is experienced, because they lead to a greater awareness of the perceptual and sensory/motor processes associated with them.

As we saw before, changes in various aspects of body schema have an effect on the way subjects perceive their own bodies. That is, changes in body schema lead to changes in body images. When a particular event or stimulus violates the information present in the body schema (as occurs during a virtual experience), the information itself becomes accessible at a conscious level [Baars, 1988]. This facilitates the process of modification and by means of the mediation of the self (which tries to integrate and maintain the consistency of the different representations of the body), it also makes it possible to influence body image.

\section{System Design and Implementation}

The Virtual Environment for Body Image Modification, VEBIM, was developed using a Thunder 100/C virtual reality systems by Virtual.sys of Milano-Italy. The Thunder $100 / \mathrm{C}$ is a Pentium based immersive VR system (100mhz, 32 mega RAM, graphic engine: Diamond Stealth 64 S3/964 4Mb VRam) including an HMD subsystem and a two-button joystick-type motion input device.

\subsection{THE DISPLAY SYSTEM}

A head mounted display with 52 degrees horizontal and 41 degrees vertical field of view provided the visual display. The HMD displays 624 lines of 210 pixel to each eye and uses LCD technology (two active matrix color LCDs). A Logitech 3D Mouse provided head tracking.

In this research we did not use a stereoscopic display. Previous researches regard stereoscopy as important because it provides the user with a good cue of depth [Barham \& McAllister, 1991]. However, the refresh rate of graphics require a decrease of $50 \%$ because of the need of two different images for each eye. Consequently, we decided against implementing a stereoscopic display. To compensate for the lack of depth cue, we included perspective cues (light and shade, relative size, textural gradient, interposition and motion parallax) in the virtual environment [Dolecek, 1994].

\subsection{MOTION INPUT SYSTEM}

The data glove-type motion input device is very common in virtual environments 
for its ability to sense many degrees of freedom simultaneously. However, the operator is also frequently confused due to difficulty in correctly using it, especially when there is a time delay contained in the feed-back loop.

To provide a easy way of motion in VEBIM, we used an infrared two-button joystick-type input device: pressing the upper button the operator moves forward, pressing the lower button the operator moves backwards. The direction of the movement is given by the rotation of operator's head.

\section{The Virtual Environment}

VEBIM is a 6-zone virtual environment developed using Sense 8 World Toolkit for Windows. As you can see in \{ \{Figure 1\}\} on the CD-ROM, VEBIM consists of two parts (zones 1-2 and zones 3-4-5-6).

The first two zones are designed both to give the subject a minimum level of skill in perceiving, moving through, and manipulating objects in VR, and to focus attention on eating and food choice.

The next four zones are designed to modify the body experience of the subject integrating the therapeutic methods used by Butter \& Cash [Butters \& Cash, 1987] and Wooley \& Wooley [Wooley \& Wooley, 1985].

Both at the beginning of zone 3 and at the end of zone 6 the subject is involved in a series of procedures/tasks aimed at assessing body experience.

Zone 1: In this zone the subject becomes familiar with the appropriate control device, the head mounted display, and how to recognize collisions. To move into the next zone the subject has to weigh himself1 by touching a virtual balance.

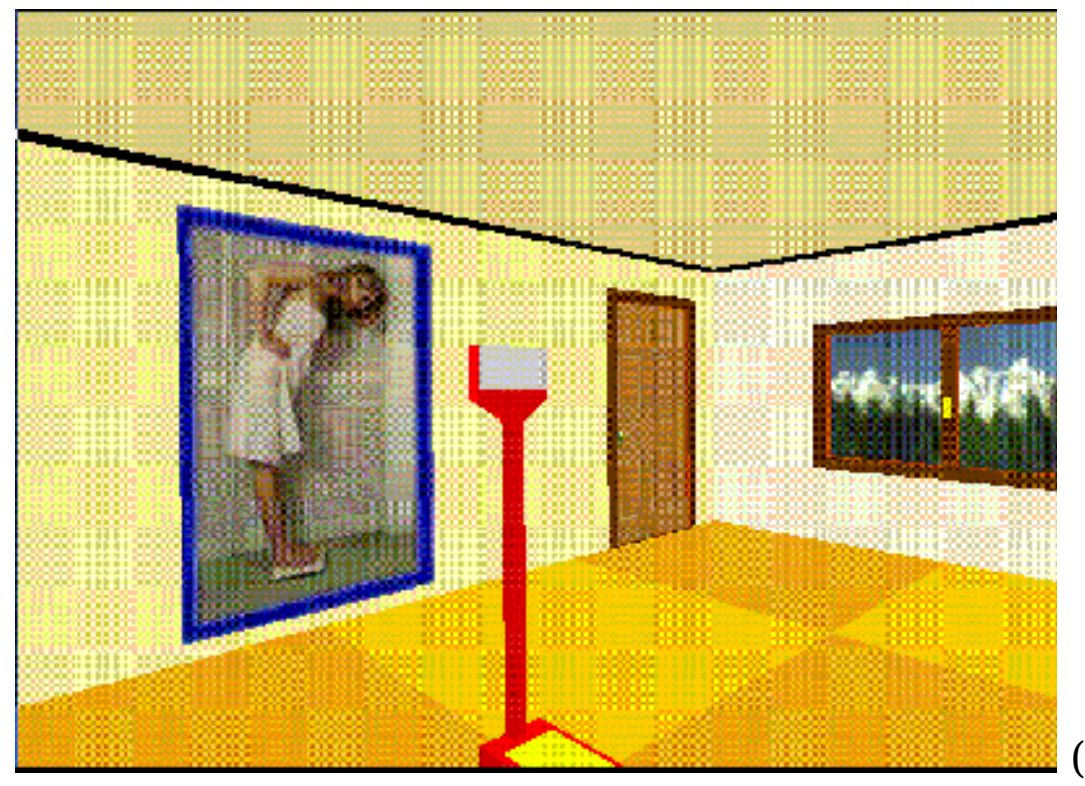

(Click on image for ext 
viewer.)

Zone $2 \mathrm{a}$ and $2 \mathrm{~b}$ : These zones show a kitchen (2a) and a office (2b). The subject can move between them and interact with the objects. Some of them are foods that the subject can take and "eat". To move into the next zone the subject has to weigh himself again. (His starting weight will be modified according to the actions made and the food eaten.)

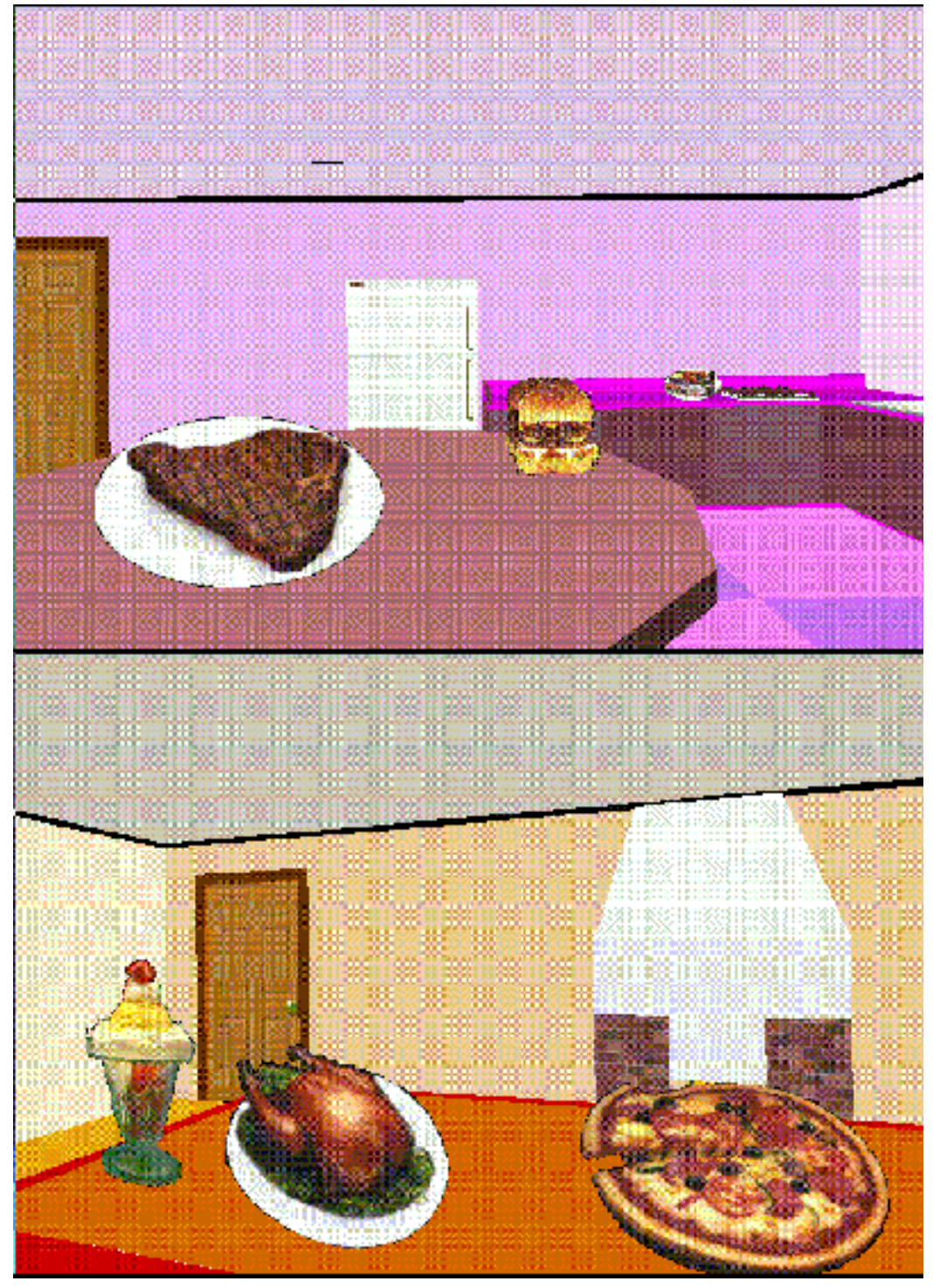

(Click on image for ext viewer.)

Zone 3: This zone consists of four corridors whose walls show images of female and male models. 


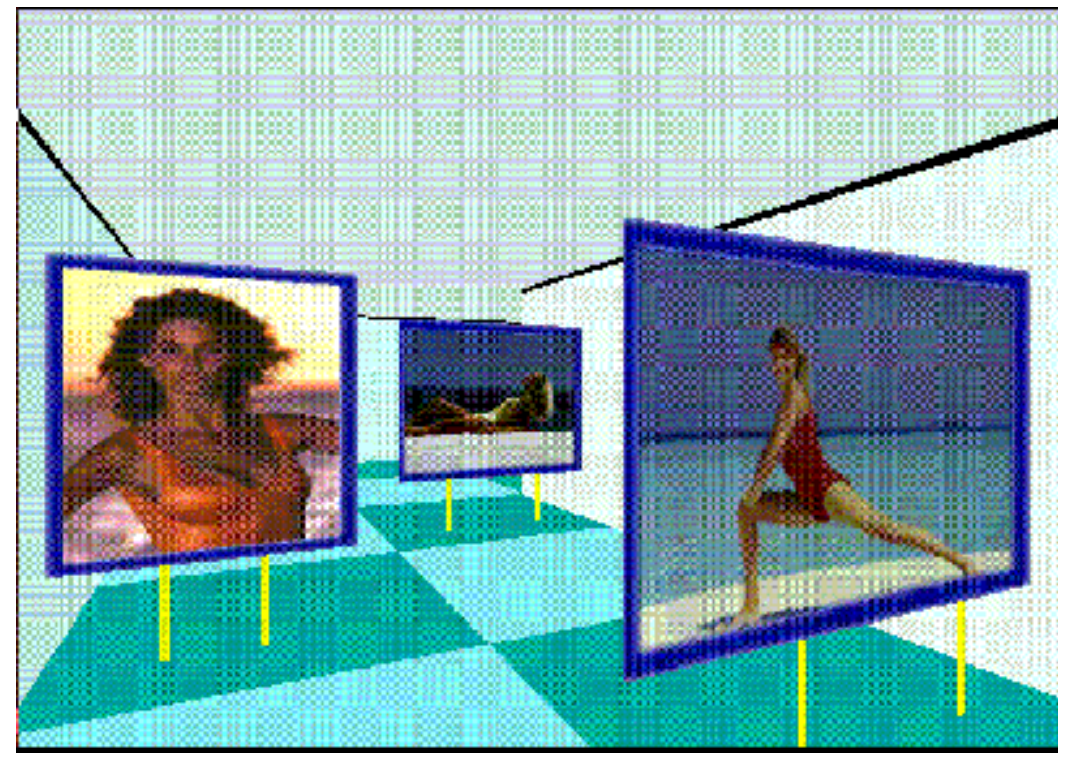

(Click on image for ext

viewer.)

Zone 4: This is a room furnished with a large mirror. Standing by it the subject can look at his real body (previously digitized using a video camera).

Zone 5: This zone consists of a long corridor ending with a room containing four doors of different dimensions. The subject can move into the last zone only choosing the door corresponding to exactly his width and height.

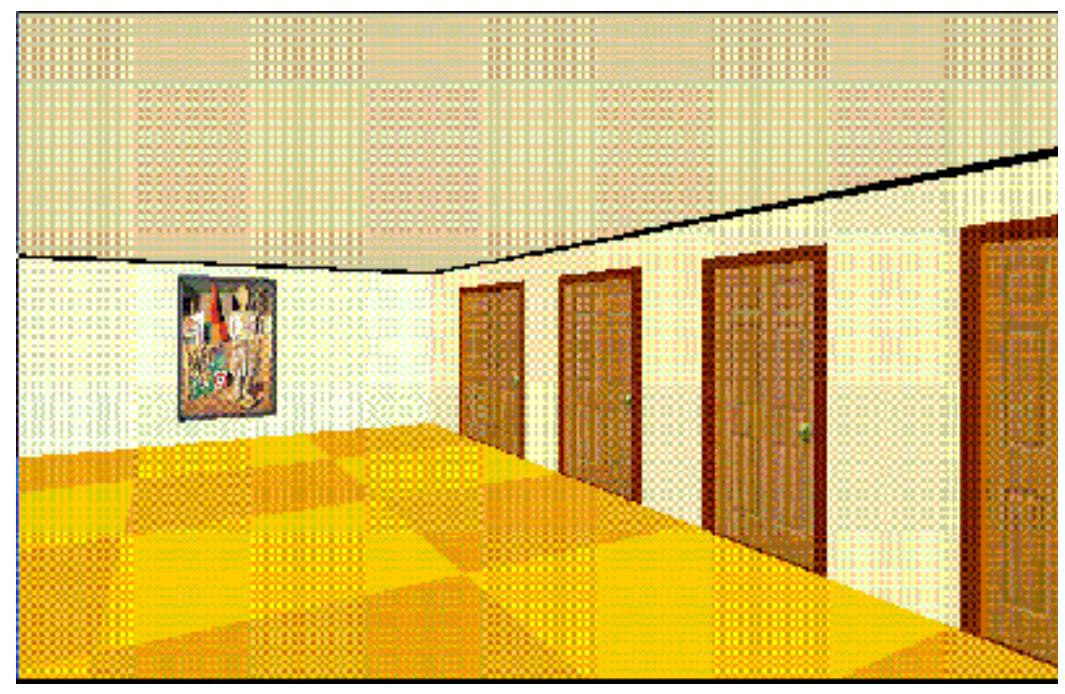

(Click on image for ext

viewer.)

Zone 6: This is a large room whose leading walls (north and south) show the body of the subject. The first image is a static one (real body) and cannot be changed, while the second one (ideal body) can be changed by the subject as he desires using a morphing-like system. 


\section{A Preliminary Study}

Until now some problems have existed with virtual reality. There are anecdotal reports that immersive VR can lead to symptoms similar to motion sickness symptoms. Visually induced motion sickness is a syndrome that occasionally occurs when physically stationary individuals view compelling visual representations of self motion. It may also occur when detectable lags are present between head movements and recomputations and presentation of the visual display in HMD. Motion sickness is characterized by a diverse set of symptoms, but is primarily exemplified by nausea and vomiting. In the case of VEBIM, with adults and adolescents as possible subjects, including people with psychological and with physical problems, the need to verify the problems associated with operating in a virtual environment has to be addressed.

The present preliminary study was designed to test VEBIM effects on a non-clinical sample. In particular, the study was designed to (1) verify the effects provoked by VEBIM on blood pressure and heart rate, and (2) verify the effects provoked by VEBIM on the body experience.

\subsection{SUBJECTS}

60 subjects (38 males and 22 females: mean age: $23.18+/-7.54$; mean weight: $67.97 \mathrm{Kg}+/-16.23$; mean height $173.4 \mathrm{~cm} \mathrm{+/-8.16)} \mathrm{attending} \mathrm{a} \mathrm{conference} \mathrm{on}$ virtual reality participated in the study.

\subsection{PROCEDURES}

All the subjects experienced VEBIM for no more than ten minutes and no less than eight. All the subjects included in the study reached zone 5 . No subject experienced zone 6 .

\subsection{MEASURES}

Before the virtual experience the subjects were fitted with a blood pressure cuff and were asked to sit quietly during a 5-minute baseline period. During this period blood pressure and heart rate were recorded. After the virtual experience and after a 10-minute post-task period blood pressure and heart rate were recorded again.

Immediately before entering the virtual environment and immediately after, all the subject were assessed for body experience using two scales:

- the Figure Rating Scale, or FRS [Thompson \& Altabe, 1991], a set of 9 male and female figures which vary in size from underweight to 
overweight.

- the Contour Drawing Rating Scale, or CDRS [Thompson \& Gray, 1995], a set of 9 male and female figures with precisely graduated increments distinguishing size.

In these tests subjects are asked to rate the figures based on the following instructional protocol: (a) current size and (b) ideal size. The difference between the ratings is called "discrepancy index" and is considered to represent the individual's level of dissatisfaction. Both scales have good test-retest reliability.

\subsection{STATISTICAL ANALYSIS}

A power calculation was made to verify the opportunity to obtain statistically significant differences between the pre- and post-VR scores. Given the low statistical power, we decided to use exact methods: a series of statistical algorithms developed by the Harvard School of Public Health that enable researchers to make reliable inferences when data are small, sparse, heavily tied or unbalanced [SPSS, 1995]. The exact method used to compare the scores was the marginal homogeneity test [Agresti, 1990].

\section{Results}

The results are summarized in the table shown.

\begin{tabular}{|l|l|l|l|l|l|l|}
\hline & \multicolumn{2}{|l|}{ Before VR } & \multicolumn{2}{l|}{ Just after VR } & \multicolumn{2}{l|}{ After 10 minutes } \\
\hline & Mean & SD & Mean & SD & Mean & SD \\
\hline $\begin{array}{l}\text { Systolic } \\
\text { Pressure }\end{array}$ & 135.73 & 20.46 & 132.37 & 19.63 & 124.33 & 18.69 \\
\hline $\begin{array}{l}\text { Diastolic } \\
\text { Pressure }\end{array}$ & 88.68 & 20.15 & 86.95 & 22.76 & 83.58 & 15.93 \\
\hline $\begin{array}{l}\text { Heart } \\
\text { rate }\end{array}$ & 74.22 & 15.87 & 72.23 & 13.21 & 72.24 & 11.68 \\
\hline
\end{tabular}

The pressure and heart rate scores indicated no significant difference before and after the VR experience. Only one of the subject experienced simulation sickness.

For the body image ratings we found a significant reduction in the FRS and CDRS discrepancy index ( $p$ less than 0.05). This means that after the VR experience the subjects increased their body satisfaction. In both cases the reduction was caused by a decrease in the "ideal body" scores. 


\section{Conclusions}

The present study shows that even a short-term application of VEBIM is able to partially reduce the level of body dissatisfaction without any major side effect. The fact that the subjects of our sample view their body as nearer to their ideal than before the procedure means that the virtual environment has induced a more realistic view of their body.

As such, the procedure might be helpful in clinical subjects to break through the "resistance" to treatment [Vandereycken, 1990], [Vandereycken et al., 1988]. Nevertheless, an alteration of the body image toward a more realistic "proportion" -- that is, closing the gap between the actual and ideal body image -- might be decisive for the long-term outcome. We assume that the virtual experience might be useful to achieve these goal, not as a magic trick, but as a catalyst in a therapeutic process.

Of course we have to test both the effects of the virtual environment on a clinical sample and how long the impact of the virtual environment will last. In this preliminary study we have limited the test to just one session, but from a therapeutic viewpoint it seems more reasonable to repeat the procedure.

\section{ACKNOWLEDGMENT}

The present work was supported by the Commission of the European Communities (CEC), in particular by the TELEMATICS program (HC 1053 Project VREPAR - Virtual Reality Environments for Psycho-neuropsychological Assessment and Rehabilitation).

The author would also like to acknowledge the following people who have contributed to the work described in this paper: Roberto Troiani, Marco Crespi and Gabriele Lissoni from Virtual.Sys, Milan; Alessandra Morosin, Paola Regazzoni, Eugenia Borgomainerio, Mirco Bolzoni, Luca Melis and Enrico Molinari from the Centro Auxologico Italiano, Piancavallo; and Carlo Galimberti from the Catholic University of Milan.

\section{BIBLIOGRAPHY}

Adame, D. D., Radell, S.A. ,Johnson, T.C., \& Cole S.P. (1991). Physical Fitness, Body Image, and Locus of Control in College Women Dancers and Nondancers. Perceptual and Motor Skllls, 72, 91-95. \{ \{ Return\}\}

Agresti, A. (1990). Categorical data analysis. New York: John Wiley and 
Sons. $\{\{$ Return $\}\}$

Allamani, A. \& Allegranzi, P. (1990). Immagine corporea: dimensioni e misure. Una ricerca clinica (Body Image: dimensions and measures. A clinic research.). Archivio di Psicologia Neurologia Psichiatria, 2, 171-195. $\{\{$ Return $\}\}$

American Psychiatric Association (1994). DSM IV: Diagnostic and Statistical Manual of Mental Disorders. Washington, D.C., APA. \{\{Return\}\}

Baars, B.J. (1988). A cognitive theory of consciousness. New York: Cambridge University Press. \{\{Return\}\}

Barham, P.T., \& Mc Allister, D.F. (1991). A comparison of stereoscopic cursors for the interactive manipulation of B-splines. Proceedings of Stereoscopic Display and Applications II, 18-26. \{\{ Return\}\}

Barrios, B.A., Ruff, G., \& York, C. (1989). Bulimia and body image: Assessment and explication of a promising construct. In W.G. Johnson (Ed.), Advances in eating disorders Vol. II. New York: Jay Press. \{\{ Return\}\}

Bruch, H. (1962). Perceptual and conceptual disturbances in anorexia nervosa. Psychosomatic Medicine, 24, 187-194. \{\{Return\}\}

Bruch, H. (1973). Eating disorders: Obesity, anorexia nervosa and the person within. New York: Basic Books. \{ \{ Return\}\}

Butters, J.W., \& Cash, T.F. (1987). Cognitive-behavioral treatment of women's body image satisfaction: A controlled outcome-study. Journal of Consulting and Clinical Psychology, 55, 889-897. \{\{ Return\}\}

Butters, J.W., \& Cash, T.F. (1987). Cognitive-behavioral treatment of women's body image satisfaction: A controlled outcome-study. Journal of Consulting and Clinical Psychology, 55, 889-897. \{\{Return\}\}

Button, E. (1986). Body size perception and response to in-patient treatment in anorexia nervosa. International Journal of Eating Disorders, 5, 617-629, (1986). \{\{ Return\}\}

Campos, J.J., Bertenthal, B.I., \& Kermoian, R. (1992). Early experience and emotional development: the emergence of wariness of heights.

Psychological Science, 3, 61-64. \{\{ Return\}\}

Casper, R.C., Halmi, K., Goldberg, S.C., Eckert, E.D., \& Davis, J.M. (1979). Disturbances in body image estimation as related to other characteristics and outcome in anorexia nervosa. British Journal of Psychiatry, 134, 60-66. 


\section{$\{\{$ Return $\}\}$}

Cioffi, G. (1993). Le variabili psicologiche implicate in un'esperienza virtuale (Psychological variables that influence a virtual experience). In G. Belotti (Ed.), Del Virtuale (Virtuality). Milano: Il Rostro. \{ \{ Return\}\}

Dasch, C. S. (1978). Relation of Dance Skills to Body Cathexis and Locus of Control Orientation. Perceptual and Motor Skills, 46, 465-466. \{ \{ Return\}\}

Davis, C., \& Cowles M. (1991). Body Image and Exercise: A Study of Relationships and Comparisons between Physically Active Men and Women. Sex Roles, 25, 33-44. \{\{ Return\}\}

Durlach, N. (1992). Virtual environment technology for training (Report No 7661). Cambridge, MA: MIT-BNN Systems and Technologies. \{\{ Return\}\}

Dolecek, Q.E. (1994). Computer-generated stereoscopic displays. John Hopkins APL Technical Digest, 15, 137-142. \{\{Return\}\}

Ellis, A. (1962). Reason and emotion in psychotherapy. New York: Lyle Stuart. $\{$ Return $\}\}$

Ellis, S.R., Kaiser, M., \& Grunwald, A. (1991). Pictorial communication in virtual and real environments. London: Taylor \& Francis. \{ \{ Return\}\}

Fisher, S. (1990). The evolution of psychological concepts about the body. In T.F. Cash, \& T. Pruzinsky (Eds.), Body Images: Development, Deviance and Change. New York: The Guilford Press. \{ $\{$ Return\}\}

Freedman, R. (1990). Cognitive-behavioral perspectives on body-image change. In T.F. Cash, \& T. Pruzinsky (Eds.), Body Images: Development, Deviance and Change. New York: The Guilford Press. \{\{Return\}\}

Gallagher, S. (1986). Body Image and Body Schema: a conceptual clarification. Journal of Mind \& Behaviour, 4, 541-554. \{\{Return\}\}

Gallagher, S. (1995). Body schema and intentionality. In J.L. Bermúdez, A. Marcel, \& N. Eilan, The body and the self. Cambridge (MA): MIT Press. $\{\{$ Return $\}\}$

Gallagher, S. (1995). Body schema and intentionality. In J.L. Bermúdez, A. Marcel, \& N. Eilan, The body and the self. Cambridge (MA): MIT Press. $\{\{$ Return $\}\}$

Garfinkel, P.E., \& Garner, D.M. (1982). Anorexia nervosa: a multidimensional perspective. New York: Brunner \& Mazel. \{\{ Return\}\} 
Harris, C. S. (1965). Perceptual adaptation to inverted, reversed, and displaced vision. Psychological Review, 72, 419-444. \{\{Return\}\}

Head, H. (1926). Aphasia and kindred disorders of speech. London: Cambridge University Press. $\{\{$ Return\}\}

Heeter, C. (1992). Being there: the subjective experience of presence. Presence: Teleoperator and Virtual Environments, 2, 262-271. \{\{Return\}\}

Hodges, L.F., Bolter, J., Mynatt, E., Ribarsky, W., \& Van Teylingen, R. (1993). Virtual environments research at the Georgia Tech GVU Center. Presence: Teleoperator and Virtual Environments, 3, 234-243.

Kearney-Cooke, A. (1989). Reclaiming the body: using guided imagery in the treatment of body image disturbances among bulimic women. In L.M. Hornyak, \& E.K. Baker (Eds.), Experiential therapies for eating disorders. New York: The Guildford Press.

Kijima, R., Shirakawa, K., Hirose, M., \& Nihei, K. (1994). Virtual sand box: development of an application of virtual environments for clinical medicine. Presence: Teleoperator and Virtual Environments, 1, 45-59.

Leuner, H. (1969). Guided affective imagery: a method of intensive psychotherapy. American Journal of Psychotherapy, 23, 4-21. \{\{Return\}\}

Reyker, J. (1977). Spontaneous visual imagery: Implications for psychoanalysis, psychopathology and psychotherapy. Journal of Mental Imagery, 2, 253-274. \{\{ Return\}\}

Roll, J.P., \& Roll, R. (1988). From eye to foot: A proprioceptive chain involved in postural control. ln G. Amblard, A. Berthoz, \& F. Clarac (Eds.), Posture and Gait: Development, Adaptation, and Modulation. Amsterdam: Excerpta Medica. $\{\{$ Return $\}\}$

Rosen, J.C. (1990). Body image disturbances in Eating Disorders. In T.F. Cash, \& T. Pruzinsky (Eds.), Body Images: Development, Deviance and Change. The Guilford Press: New York. \{ \{ Return\}\}

Ruggieri, V., Milizia, M., Sabatini, N., \& Tosi, M.T. (1983). Body perception in relation to muscular tone at rest and tactile sensitivity to tickle.

Perceptual and Motor Skills. \{ \{ Return $\}\}$

Sabatini, N., Ruggieri, V., \& Milizia, M. (1984). Barrier and penetration scores in relation to some objective and subjective somesthetic measures. Perceptual and Motor Skills, 59, 195-202. \{ \{ Return\}\} 
Sadowsky, J., \& Massof, R.W. (1994). Sensory engineering: the science of synthetic environments. John Hopkins APL Technical Digest, 15, 99-109. $\{\{$ Return $\}$ \}

Schilder, P. (1950). The image and appearance of the human body. New York: International Universities Press. $\{$ Return $\}\}$

Skrinar, G.S., Bullen, B.A., Cheek, J.M., McArthur, J.W., \& and Vaughan, L. K. (1986). Effects of endurance training on body-consciousness in women. Perceptual and Motor Skills, 62, 483-490. \{\{ Return\}\}

SPSS (1995). SPSS Exact tests 6.1 for Windows. Chicago: SPSS. $\{\{$ Return $\}$ \}

Steuer, J. (1992). Defining virtual reality: dimensions determining telepresence. Journal of Communication, 42, 73-93. \{\{ Return\}\}

Stunkard, A., \& Burt, V. (1967). Obesity and the body game: II. Age of onset of disturbances in body image. American Journal of Psychiatry, 123, 1447-1447. \{\{Return\}\}

Stunkard, A., \& Mendelson, M. (1961). Disturbances in body image of some obese persons, American Journal of Dietology, 38, 57-63. \{ \{ Return\}\}

Thompson, J.K. (1990). Body image disturbance: Assessment and Treatment. Elmsford (NJ): Pergamon Press. \{ \{ Return\}\}

Thompson, J.K. (1990). Body image disturbance: Assessment and Treatment. Elmsford (NJ): Pergamon Press. \{ \{ Return\}\}

Thompson, J.K. (1992). Body Image: Extent of disturbance, associated features, theoretical models, assessment methodologies, intervention strategies, and a proposal for a new DSM IV diagnostic category - Body Image Disorder. In M. Hersa, R.M. Eisler, \& P.M. Miller (Eds.), Progress in behavior modification. Sycamore (IL): Sicamore,. \{\{ Return\}\}

Thompson, J.K. (1995). Assessment of Body Image. In D.B. Allison (Ed.), Handbook of Assessment Methods for Eating Behaviors and Weight Related Problems. Thousand Oaks, CA: Sage. $\{\{$ Return $\}\}$

Thompson, J.K., \& Altabe, M.N. (1991). Psychometric qualities of the Figure Rating Scale. International Journal of Eating Disorders, 10, 615-619. \{ \{ Return\}\}

Thompson, J.K., Berland, N.W., Linton, P.H., \& Weinsier, R. (1986). Assessment of body distortion via a self-adjusting light beam in seven 
eating disorders groups. International Journal of Eating Disorders, 7, 113-120. \{\{ Return\}\}

Thompson, M.A, Gray, J.J. (1995). Development and Validation of a new body-image assessment scale. Journal of Personality Assessment, 2, 258-269. \{ \{ Return\}\}

Valtolina, G., Molinari, E., Borgomainerio, E., \& Riva, G. (1994). Body size estimation in anorexia nervosa. In AA.VV., Advancements in Diagnosis and Treatment of Anorexia and Obesity. Rome: SIS.DCA. \{\{Return\}\}

Vandereycken, W., Probst, M., \& Meermann, R. (1988). An experimental video-confrontation procedure as a therapeutic technique and a research tool in the treatment of eating disorders. In Pirke, K.M., Vandereycken, W., \& Ploog, D. (Eds.), The psychobiology of bulimia nervosa. Heidelberg: Springer-Verlag. $\{$ Return $\}\}$

Vandereycken, W., Probst, M., \& Meermann, R. (1988). An experimental video-confrontation procedure as a therapeutic technique and a research tool in the treatment of eating disorders. In Pirke, K.M., Vandereycken, W., \& Ploog, D. (Eds.), The psychobiology of bulimia nervosa. Heidelberg: Springer-Verlag. \{\{ Return $\}\}$

Vandereycken, W. (1990). The relevance of body-image disturbances for the treatment of bulimia. In M. M. Fichter (Ed.), Bulimia nervosa. Basic research, diagnosis and treatment. Chichester \& New York: Wiley. $\{\{$ Return $\}\}$

Wolpe, J. (1958). Psychotherapy for reciprocal inhibition. Palo Alto CA: Stanford University Press. $\{$ \{Return $\}\}$

Wooley, S.C., \& Wooley, O.W. Intensive out-patient and residential treatment for bulimia. In Garner, D.M., \& Garfinkel, P.E. (Eds.), Handbook of psychotherapy for anorexia and bulimia. New York: Guilford Press. $\{\{$ Return $\}\}$

Wooley, S.C., \& Wooley, O.W. Intensive out-patient and residential treatment for bulimia. In Garner, D.M., \& Garfinkel, P.E. (Eds.), Handbook of psychotherapy for anorexia and bulimia. New York: Guilford Press. $\{\{$ Return $\}\}$

\section{CONTACT INFORMATION}

Giuseppe Riva Applied Technology for Psychology Lab. 
Centro Auxologico Italiano

P.O. Box 1

28044 Intra (NO) - Italy

Phone: +39-323-580280

FAX:+39-323-587694

Email: auxo.psylab@mail.skylink.it

$\{$ return $\}\}$

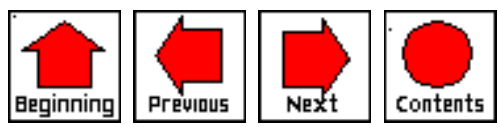

